\title{
Allelopathic Potential of Rice Straw Incorporation on Weed Emergence in Rice Cultivars
}

\author{
Dr. (Mrs.) T. Geetha Jebarathnam Kuttibai \\ Department of Agronomy, JSA College of agriculture and technology, Tholudur, Tamil nadu, India
}

\begin{abstract}
Laboratory experiment was conducted to evaluate the effect of in corporation of rice straw on the germination of different rice cultivars viz: ADT 36,ADT 38,ADT49,CO43.Further the allelopathic impact of crop residues on weed count and weed biomass was also registered. Different rates of incorporation was tried and higher the rate of incorporation, higher the inhibitions on rice and weed observations. Reduction in the performance of rice seed germination and growth parameters was observed with increased rice straw incorporation in all the four rice cultivars tried. Perhaps the rice straw incorporation had an influence on the biomass of rice cultivars too. Supporting research evidences also reveals that allelopathic effect of rice straw on rice and weed performance can stand as a remarkable achievement for recycling rice straw in rice producing countries.
\end{abstract}

KEYWORDS: Allelopathic, Rice Cultivars, Weed Emergence

\section{INTRODUCTION}

Achieving food security has become a tremendous task to mankind in order to satisfy the dietary requirements of the exploding population. Hence maximizing yield is the only target in modern agriculture, which satisfies the food demand but directly or indirectly it results in negative impact in the quality of produce and environment too. The present system of rice production requires the use of agrochemicals such as fertilizers, pesticides, herbicides often in heavy doses that are harmful to the environment as they spill into the water bodies and worse get deposited in bodies of the human beings and animals in toxic proportions.

The weed control is an expensive practice and is a major constraint in rice cultivation. Most agriculture systems collectively use 3 metric tons of herbicide per year. The use of herbicides causes another problem that of the selective growth of weeds. In this regard allelopathic effect of different plants is drawing attention of many researchers in the recent past. South and South East Asia are predominant in rice cultivation, being accepted worldwide as the staple food. In view of the increased demand for labour and escalation in labour costs the traditional practice of transplanting is shifted to direct seeding (Pandey and Velesco, 1999). Cost of weed control could be a major constraint to the widespread adoption of direct seeding methods. Therefore there is need to develop a sustainable weed management approach by combining a variety of agronomic practices to suppress weeds and reduce the usage of herbicide.

Allelopathy in rice can be used as a method of biological control of weeds in the rice ecosystem. Hence the present work is aimed to find out the impact of rice straw incorporation on the crop and weed seeds germination and plant growth biometrics in order to reduce the use of herbicides.

\section{MATERIALS AND METHODS}

Experiments were taken up in the, laboratory, with seeds of four rice cultivars as main treatments viz. ADT36, ADT38, ADT49, C043. The sub treatments include the incorporation of rice straw at five different concentrations compared with control. The different rates of paddy straw incorporation were, $100 \mathrm{~g} / \mathrm{m}^{2}, 200 \mathrm{~g} / \mathrm{m}^{2}, 500 \mathrm{~g} / \mathrm{m}^{2}, 1 \mathrm{~kg} / \mathrm{m}^{2}$ and control with no paddy straw. The experiment was laid on shallow trays of $30 \times 22.5 \mathrm{~cm}$ size, and the quantity of soil required to be filled, $1 \mathrm{~kg} / \mathrm{tray}$ and was thoroughly mixed. The soil filled trays were moistened to take up sowing. Prior to sowing, rice straw were taken, cut into small pieces and incorporated in trays as recommended; further the trays were left for a week allowing the incorporated straw to decompose. The selected four rice cultivar seeds were sown in the trays @ 200 seeds / tray and replicated thrice. The observations on germination percentage was done on 7 DAS and the weed count was taken at 15 DAS. At 30 DAS the seedlings were uprooted 


\section{International Journal of Current Science Research and Review}

ISSN: 2581-8341

Volume 04 Issue 12 December 2021

DOI: 10.47191/ijcsrr/V4-i12-07, Impact Factor: 5.825

and shoot length, root length, leaf length and plant biomass were recorded to compare the allelopathic impact on the cultivars tried. The data was analysed using the analysis of variance and worked out as $0.5 \%$ as suggested by Panse and Sukhatme (1978).

\section{RESULTS AND DISCUSSION}

The effect of rice straw extracts on rice seed germination is shown in Table: 1. The germination percentage, seedling root and shoot growth was more affected by the extracts of incorporation. In fact the percentage growth reduction increased with the concentration, and root growth was more sensitive than shoot growth. The results clearly indicated that rice straw was very toxic at all levels, with significant reduction in seedling root and shoot growth.

The results were in conformity with Olofsdotter et al., (1999), referring that the rice plant exhibited allelopathic activity during their investigation with 111 rice cultivars under field conditions. Phenolic acids eg. P- hydroxybenzoic, vanillic, pcoumaric and ferulicacids were identified as the main allelo chemicals in rice and its residues. Of all the four varieties tried, the germination percentage was substantially better in ADT 36, with less allelopathic impact towards rice straw incorporation rather. The percentage of reduction in germination gradually decreased with the increase in concentration of the rice straw. The least germination percentage of $36 \%$ was recorded in ADT 38 at the concentration of $1 \mathrm{~kg} \mathrm{~m}^{-2}$ of rice straw incorporation.

Similarly in the laboratory experiment conducted the influence of rice straw incorporation on growth parameters of the rice cultivars was clearly obvious and hence the shoot length, root length and leaf length, of the emerged rice seedlings recorded were significantly having an inhibitory impact due to rice straw incorporation, Reduction in the performance of the growth parameters was observed with increased concentration of rice straw incorporation in all the four rice cultivars evaluated. The maximum reduction in the growth parameters was observed with ADT38 variety; for instance, recording $2.8 \mathrm{~cm}$ of leaf length as against 4.35, 4.15 and $6 \mathrm{~cm}$ in ADT 36, ADT49, C043. The earlier reports were concurrent to the present findings (Chung et al., 2003; Mattice et al., 2001). Numerous phytotoxins such as cytokinins, diterpenoids, fattyacids, flavanones, glycopyranosides, indoles, mamilactones (A\&B), oxyzalexines, phenols, phenolic acids, resorcinols and stigmaslanols have been identified as growth inhibitors in rice which obviously contributed for the allelopathic effect on rice parameters. However, the actual modes of action, of these compounds as well as other potential rice phytotoxins in nature are not well understood (Khanh et al., 2007).

Perhaps apart from the inhibition observed on the growth parameters, the application of rice straw extract had an influence on the biomass of the cultivars too (Table: 2). The cultivar C043 recorded the least biomass of $9.5 \mathrm{gms} /$ tray for $1 \mathrm{~kg} \mathrm{~m}^{-2}$ incorporation of rice straw that was on par with ADT38 recording $12 \mathrm{~g} /$ tray. Significant inhibition in the volume of the plant biomass was observed in ADT 36, ADT 49 varieties that were next in order.

The influence of rice straw incorporation on the weed count was shown in Fig: 2. It was obvious that the rice straw extract applied at different concentrations significantly decreased the weed count / tray as compared with control. The trend was similar to that of the other parameters (i.e.) in trays were ADT38 was sown 46.3 to $73.3 \%$ of reduction in the weed count was observed. However application of higher concentrations of rice straw remarkably inhibited the weed seed germination in all the rice cultivars. Such results might suggest that the inhibitory effect of rice straw extract on controlling the weeds might be partially due to the extract containing certain phytotoxic compounds which can be released by the residues and other agro ecosystem factors, existed in the vicinity. In fact the weed biomass also decreased corresponding to the increase in rice straw (Fig: 1) These evidences can reconcile with the results which revealed that rice straw contains some phenolic compounds and or certain soluble allelo chemicals which are considered as the key factor of allelopathic activity in rice straw for suppressing growth and development of wide range of broad and narrow leaved weeds in many crops. Supporting results were also obtained by Pramanik et al., (2001) who mentioned that rice straw extracts contain growth inhibitors. Recently further supporting evidences were obtained by Chung et al., (2003) who found that phyto toxicity of extracts of rice straw and different parts of rice was promising on inhibiting the seed germination and seedling growth of Echinochloa crusgalli. Therefore the incorporation of rice straw resulted in suppressing growth and development of a wide range of weeds. This could be attributed that the rice straw serves either as a physical barrier or as an inhibitor endowed without allelopathic principles against developmental processes and progression of associated weeds.

Thus the present works on rice straw incorporation reveals that, itself being the nature's gift with excellent source of allelo chemicals could be useful in multi disciplinary approaches, so as to formulate potential natural herbicides either for controlling weeds and / or minimizing the herbicidal doses evidently. Such studies indicate that using the straw wastes for 


\section{International Journal of Current Science Research and Review}

ISSN: 2581-8341

Volume 04 Issue 12 December 2021

DOI: 10.47191/ijcsrr/V4-i12-07, Impact Factor: 5.825

IJCSRR@ 2021

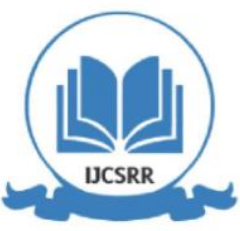

www.ijcsrr.org

controlling a large number of weeds, in many crops, can stand as a remarkable achievement for recycling rice straw in rice producing countries which will be reflected on reducing the environmental pollution impact.

Table: 1 Effect of Rice Straw Incorporation on Rice Seed Germination

\begin{tabular}{|c|c|c|c|c|c|c|}
\hline \multirow{2}{*}{$\begin{array}{l}\text { S. } \\
\text { No. }\end{array}$} & \multirow{2}{*}{ Variety } & \multicolumn{5}{|c|}{ Rice straw incorporation } \\
\hline & & Control & $100 \mathrm{gm} / \mathrm{m}^{2}$ & $200 \mathrm{gm} / \mathrm{m}^{2}$ & $500 \mathrm{gm} / \mathrm{m}^{2}$ & $1 \mathrm{~kg} / \mathrm{m}^{2}$ \\
\hline 1. & ADT 36 & 195 & 184 & 179 & 166 & 131 \\
\hline 2. & ADT 38 & 186 & 96 & 86 & 86 & 78 \\
\hline 3. & ADT49 & 186 & 156 & 148 & 102 & 94 \\
\hline 4. & $\mathrm{C043}$ & 191 & 178 & 143 & 130 & 60.9 , \\
\hline \multicolumn{2}{|c|}{ Mean } & 130.5 & 110.5 & 100.5 & 89.0 & 64.75 \\
\hline \multicolumn{2}{|c|}{$\mathrm{LSD}(\mathrm{P}=0.05)$} & 26.3 & 22.5 & 18.6 & 27.9 & 10.8 \\
\hline
\end{tabular}

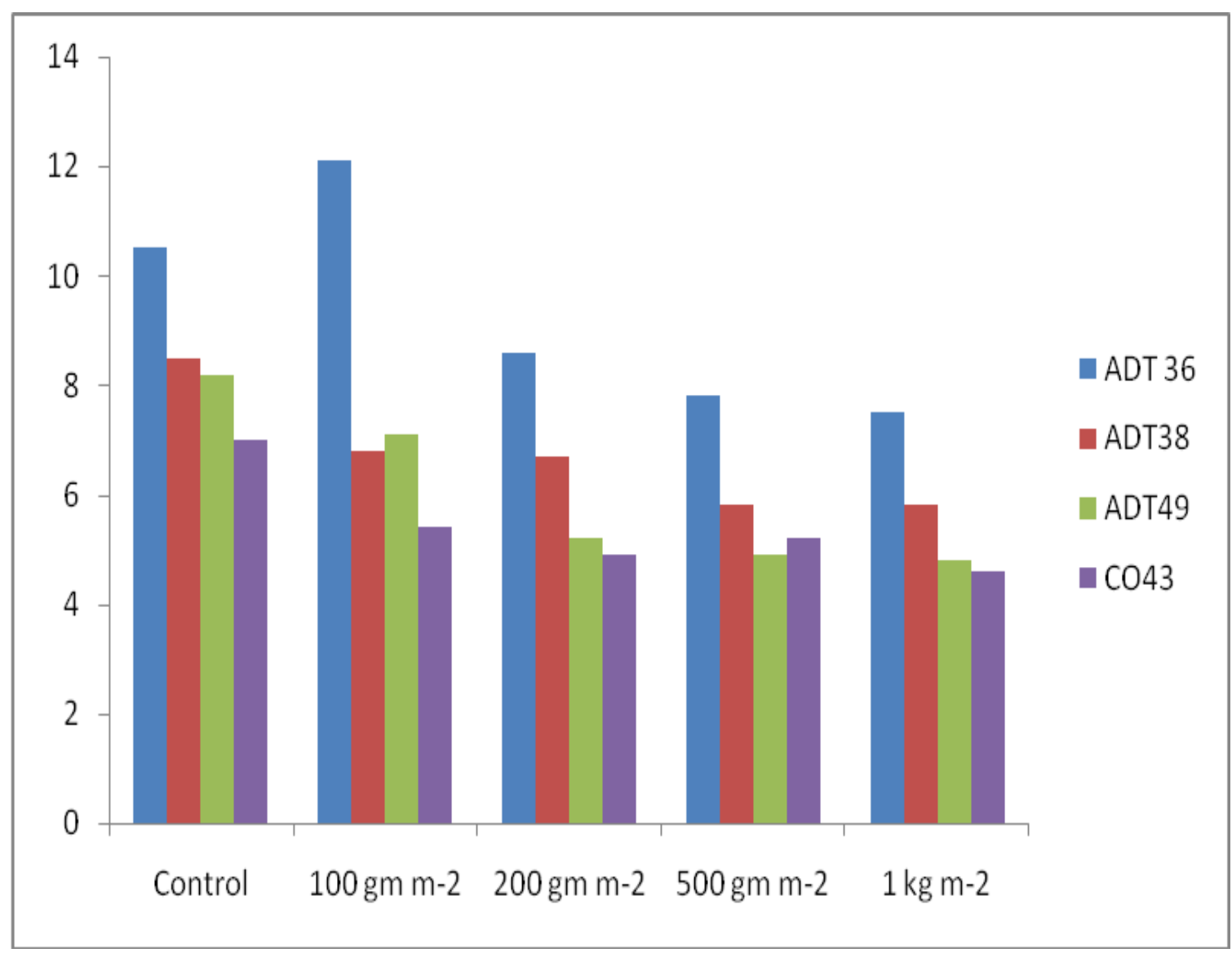

Fig 2: Effect of Rice Straw Incorporation on Weed Biomass Production (gms /tray) 
International Journal of Current Science Research and Review

ISSN: 2581-8341

Volume 04 Issue 12 December 2021

DOI: 10.47191/ijcsrr/V4-i12-07, Impact Factor: 5.825

IJCSRR @ 2021

www.ijcsrr.org

Table: 2 Effect of Rice Straw Incorporation on Plant Biomass (Gms/Tray)

\begin{tabular}{|c|c|c|c|c|c|c|}
\hline \multirow{2}{*}{$\begin{array}{l}\text { S. } \\
\text { No. }\end{array}$} & \multirow{2}{*}{ Variety } & \multicolumn{5}{|c|}{ Rice straw incorporation } \\
\hline & & Control & $100 \mathrm{gm} / \mathrm{m}^{2}$ & $200 \mathrm{gm} / \mathrm{m}^{2}$ & $500 \mathrm{gm} / \mathrm{m}^{2}$ & $1 \mathrm{~kg} / \mathrm{m}^{2}$ \\
\hline 1. & ADT 36 & 35.5 & 38 & 27 & 25.5 & 22 \\
\hline 2. & ADT 38 & 27 & 18 & 18 & 16 & 16 \\
\hline 3. & ADT49 & 25.5 & 18.5 & 13.5 & 12.5 & 12 \\
\hline 4. & $\mathrm{C} 043$ & 20 & 13.5 & 12.5 & 11 & 9.5 \\
\hline \multicolumn{2}{|c|}{ Mean } & 31.5 & 22.0 & 17.75 & 14.25 & 14.87 \\
\hline \multicolumn{2}{|c|}{$\operatorname{LSD}(\mathrm{P}=0.05)$} & 4.5 & 4.62 & 5.3 & 4.34 & 5.1 \\
\hline
\end{tabular}

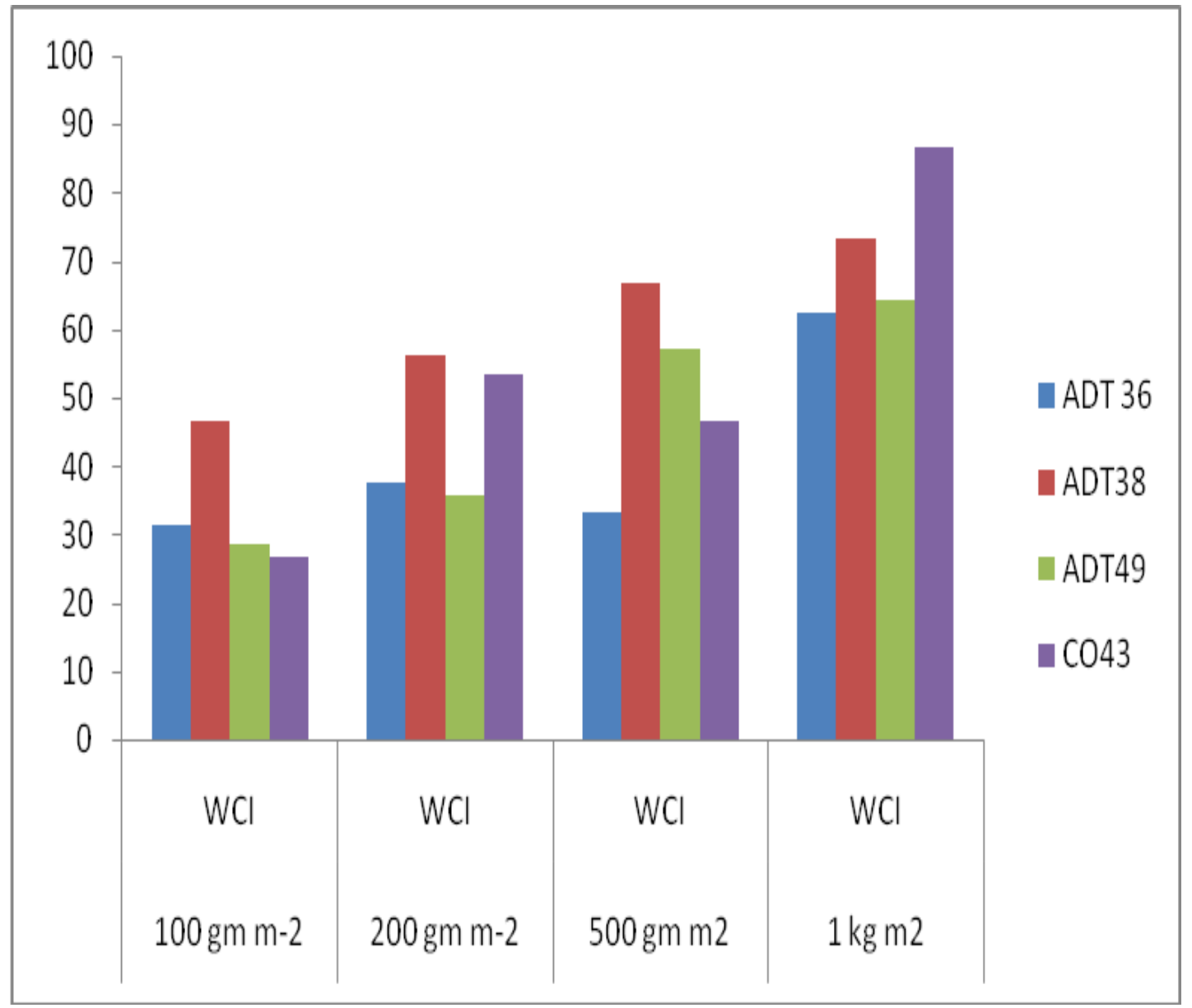

Fig 1: Effect of Rice Straw Incorporation on Weed Control Index

\section{REFERENCES}

1. Chung, I.M., K.H. Kim., J.K Abn, S.B. Lee, S.H. Kim and SJ. Hahn, 2003. Comparison of Allelopathic Potential of Rice Leaves, Straw, and Hull Extracts on Barnyardgrass. Agronomy J., 95 : 1063-70.

2. Khanh, T.D., Chung, M.I., Tawata, S-, Xuan, T.D. (2007). Allelopathy for weed management in sustainable agriculture, CAB Reviews : Perspectives in Agriculture, Veterinary Science, Nutrition and Natural Resources. 34,17. 


\section{International Journal of Current Science Research and Review}

ISSN: 2581-8341

Volume 04 Issue 12 December 2021

DOI: 10.47191/ijcsrr/V4-i12-07, Impact Factor: 5.825

IJCSRR@ 2021

WwW.ijcsrr.org

3. Mattice, J.D., R.H. Dilday, E£. Gbure and B.W. Skulman, 2001, Barnyardgrass growth inhibition with rice using high performance liquid chromatography to identify rice accession activity. Agronomy J. 93: 8 - 11.

4. Olofsdotter, M., Naverez, D. and Resbulanam, M. (1999) Weeds - suppressing rice cultivars - does allepoahty play a role? Weed Research 39,441-69.

5. Pandey.S and Velasco. H (1999) Economics of direct seeding in Asia; patterns of adoption and research properties. Inl.Rice Res. Notes 24,6-110

6. Pramanik, M.H., Y. Minesaki, T. Yamamoto, Y. Matsui and H. Nakano 2001. Growth inhibitors in rice-straw extract and their effects on chines milk vetch (Astragelus sincins) seedlings weed Biol, and Manag. 76p-:133-8.

Cite this Article: Dr. (Mrs.) T. Geetha Jebarathnam Kuttibai (2021). Allelopathic Potential of Rice Straw Incorporation on Weed Emergence in Rice Cultivars. International Journal of Current Science Research and Review, 4(12), 1659-1663 